\title{
CARACTERISTICAS DO PORTFÓLIO BIBLIOGRÁFICO SOBRE EDUCAÇÃO AMBIENTAL E EDUCAÇÃO PARA A SUSTENTABILIDADE
}

\section{LÚCIA DE FÁTIMA REBOUÇAS DE SOUZA}

Graduanda em Administração, Universidade Federal Rural do Semi-Árido - UFERSA, Brasil.

Bolsista de Iniciação Científica do Programa Institucional de Iniciação Científica da Universidade Federal Rural do Semi-Árido - UFERSA, Brasil.

luciasouzaadm@hotmail.com

\section{THAISEANY DE FREITAS RÊGO}

Doutora em Administração, Pontifícia Universidade Católica do Paraná - PUC-PR, Brasil.

Professora da Universidade Federal Rural do Semi-Árido - UFERSA, Brasil.

thaiseany@ufersa.edu.br

\section{LÍLIAN CAPORLÍNGUA GIESTA-CABRAL}

Doutora em Administração, Universidade Federal do Rio Grande do Sul - UFRGS, Brasil.

Professora da Universidade Federal Rural do Semi-Árido - UFERSA, Brasil.

Docente do Mestrado em Ambiente, Tecnologia e Sociedade da Universidade Federal Rural do Semi-Árido UFERSA, Brasil.

ligiesta@gmail.com

\section{Resumo}

O artigo se propõe a mapear as características do portfólio bibliográfico sobre "Educação Ambiental" e "Educação para a Sustentabilidade" em três grandes eventos da área de Administração: EnANPAD, ENGEMA e Ecoinovar. Nos eventos, identificaram-se sessenta e um artigos que contêm "Educação" no título e tratam de sustentabilidade e/ou meio ambiente. Na análise, observaram-se informações sobre aspectos metodológicos, autores e instituiç̧ões, sendo esses dois últimos utilizados nos gráficos de redes de cooperação. A dicotomia entre os termos "Educação Ambiental" (EA) e "Educação para a Sustentabilidade" (EpS) comprometeu a definição conceitual dos artigos. Em geral, os autores que optaram por um termo ou outro já tinham sua decisão tomada, têm formação dedicada ao tema que escolheram e desenvolvem ações de ensino, extensão e/ou pesquisa sobre ele. A maioria dos artigos optou pelo uso de EA (70,49\%), já 16,39\% optaram por EpS e 13,11\% intercalavam os termos EA e EpS nos textos.

Palavras-chave: educação ambiental, educação para a sustentabilidade, portfólio bibliográfico, bibliometria. 


\title{
BIBLIOGRAPHIC PORTFOLIO CHARACTERISTICS ON ENVIRONMENTAL EDUCATION AND EDUCATION FOR SUSTAINABILITY
}

\begin{abstract}
This article aims to map the characteristics of the bibliographic portfolio on "Environmental Education" and "Education for Sustainability" in three major events of Administration: EnANPAD, ENGEMA, and Ecoinovar. We identified 61 articles that contained "Education" in the title and discussed sustainability and/or the environment. On the analysis, we found information about methodological aspects, authors and institutions - the last two used in cooperation network graphics. The dichotomy between the terms "Environmental Education" (EE) and "Education for Sustainability" (EfS) affected the conceptual definition of the articles. In general, authors who opted by one term or the other had already made their decision, have scientifically dedicated to the field of the chosen themes, and usually undertake teaching, extension and/or research actions in this field. Most articles opted for EA (70.49\%), while $16.39 \%$ chose EfS and $13.11 \%$ intercalated the terms EA and EfS in their texts.
\end{abstract}

Keywords: environmental education, education for sustainability, bibliographic portfolio, bibliometrics.

\section{CARACTERISTICAS DEL PORTAFÓLIO BIBLIOGRÁFICO SOBRE EDUCACIÓN AMBIENTAL Y EDUCACIÓN PARA LA SOSTENIBILIDAD}

\section{Resumen}

El artículo se propone mapear las características del portafolio bibliográfico sobre "Educación Ambiental" y "Educación para la Sustentabilidad" en tres grandes eventos de Administración: EnANPAD, ENGEMA y Ecoinovar. En los eventos, se identificaron 61 artículos que contienen "Educación" en el título y tratan de sustentabilidad y/o medio ambiente. En el análisis, se observaron informaciones sobre metodología, autores e instituciones, siendo estos dos últimos utilizados en gráficos de redes de cooperación. La dicotomía entre los términos "Educación Ambiental" (EA) y "Educación para la Sustentabilidad" (EpS) comprometió la definición conceptual de los artículos. En general, los autores que optaron por un término ya tenían su decisión tomada, tienen formación dedicada al tema que escogieron y desarrollan acciones de enseñanza, extensión y/o investigación sobre él. La mayoría de los artículos optó por el uso de EA (70,49\%), ya 16,39\% optaron por EpS y 13,11\% intercalaban los términos EA y EpS en los textos. Palabras clave: educación ambiental, educación para la sustentabilidad, portfolio bibliográfico, bibliometría. 


\section{INTRODUÇÃO}

Debates acerca do meio ambiente têm sido constantes nos últimos anos. Em tempos em que a informação tem papel cada vez mais relevante, a educação representa a possibilidade de motivar e sensibilizar as pessoas para modificar as configurações de participação em de defesa da qualidade de vida (Jacobi, 2003).

Neste contexto, dada a relevância do papel da educação, seja em abordagens formais ou informais, científicas ou técnicas, a Educação Ambiental (EA) e a Educação para a Sustentabilidade (EpS) têm ganhado espaço em discussões e pesquisas (Côrtes \& Rodrigues, 2016; Figueiró, Bittencourt \& Schutel, 2016; Guerra, Garcia, Lima, Barbosa, Heerdt, \& Berchin, 2016; Mckeown \& Hopkins, 2007; Monroe, 2012; Organização das Nações Unidas para a Educação, a Ciências e a Cultura, 2017; Sertling, 2016; Sidiropoulos, 2014; Sterling, 2014).

Em uma perspectiva institucional, parte da consolidação da EA se deu a partir da Conferência Intergovernamental sobre Educação Ambiental, organizada pela Organização das Nações Unidas para a Educação, a Ciências e a Cultura (UNESCO, 1977) em Tbilisi, embora desde a sua origem já tivesse outros eventos subsidiando sua elaboração. A partir de então, seu conceito foi tendo diversas constituições e novas conceituações, contextualizadas e atualizadas à medida que o tempo passava a ser outro. No Brasil, a EA possui marcos normativos e políticas públicas para o seu incremento, como a Lei n. 9.795 (1999), que fundamenta a Política Nacional de Educação Ambiental (PNEA), o Decreto n. 4.281 (2002), que a regulamenta, o Programa Nacional de Educação Ambiental (ProNEA), que visa promovê-la, e a Resoluc, aõ n. 2 (2012), que institui as Diretrizes Curriculares Nacionais (DCNs) de Educação Ambiental.

Em paralelo a essa construção histórica, um outro conceito emerge e ganha novos adeptos, o da Educação para a Sustentabilidade ou Educação para o Desenvolvimento Sustentável (EDS), sugerindo que o conceito de EA é restrito apenas à ação e preocupação ambiental, deixando de contemplar outros elos do Desenvolvimento Sustentável. Dessa forma, o conceito ganha força com o estabelecimento por parte Assembleia Ceral das Nações Unidas da "Década da Educação para o Desenvolvimento Sustentável" de 2005 a 2014 (UN Decade of Education for Sustainable Development), tendo a UNESCO como principal liderança nesse processo (UNESCO, 2005).

Embora tenha origens no campo institucional, os processos de ensino e aprendizagem envolvendo as questões socioambientais e de sustentabilidade também têm sido amplamente discutidos na área de administração, não só enfocando a forma como é trabalhado no ensino superior (Higgins \& Thomas, 2016; Figueiró et al., 2016; Guerra et al., 2016; Sidiropoulos, 2014), quanto como os processos educativos afetam a gestão socioambiental empresarial (Tramarico, Salomon, \& Marins, 2017; Jabbour, 2015; Giesta, 2009; Heimlich, 2007).

Com esta eventual discrepância de conceitos, diferença de origens e aplicações, o que a área de administração tem produzido sobre Educação Ambiental/para sustentabilidade? Quais são as escolhas teóricas? Quais contextos são relevantes para essa comunidade acadêmica? Assim, o presente estudo se propõe a responder a seguinte problemática: Quais as características do portfólio bibliográfico das contribuições científicas dos maiores eventos da área de Administração para a temática "Educação Ambiental" e "Educação para a Sustentabilidade"? Tendo em vista esses questionamentos, esta pesquisa objetiva mapear, por meio de um estudo bibliométrico, o que vem sendo produzido sobre "Educação Ambiental" e "Educação para a Sustentabilidade" em três grandes eventos da área de Administração: Encontro da Associação Nacional de Pós-graduação e Pesquisa em Administração (EnANPAD), Encontro Internacional sobre Cestão Empresarial e Meio Ambiente (ENCEMA) e Fórum Internacional Ecoinovar (Ecoinovar). 
Destaca-se que o desenvolvimento de trabalhos acadêmicos fundamentados nos preceitos da bibliometria, e considerando os eventos supracitados, permite identificar o que se produz sobre 0 assunto em ambientes de ampla discussão acadêmica (Araújo, 2006). Ademais, permite identificar quais áreas estão saturadas ou carecem um maior aprofundamento ou realização de novos estudos. Quando se trata da temática de "Educação Ambiental" e/ou "Educação para a Sustentabilidade", pode-se reunir elementos que indiquem se o uso das terminologias supracitadas está adequado às definições propostas e traçar qual a base conceitual utilizada pelos pesquisadores da área.

\section{EDUCAÇÃo AMBIENTAL E EDUCAÇÃo PARA A SUSTENTABILIDADE}

No campo da Educação Ambiental, percebe-se a adoção de diferentes discursos sobre a EA e que os autores propõem múltiplas maneiras de configurar e de praticar a ação educativa neste campo (Sauvé, 2005). Na percepção de Dias (2004, p. 98), “... a evolução dos conceitos de EA está diretamente relacionada com a evolução do conceito meio ambiente e ao modo como este era percebido". A variedade de propostas e denominações reflete os diferentes entendimentos referentes ao meio ambiente, às causas atribuídas aos problemas ambientais e ao que se espera da ação educativa para a resolução desses problemas. Isso explica a existência de diferentes propostas de EA, cada qual construída em torno de uma determinada concepção de meio ambiente (Barbieri \& Silva, 2011b).

No que se refere à trajetória do processo de institucionalização e inserção da EA em âmbito planetário, Jacobi (2005) afirma que houve três momentos marcantes: a Conferência de Estocolmo, em 1977, a Conferência Intergovernamental sobre Educação Ambiental em Tbilisi, na Geórgia, e a Rio-92, em que foi redigido o "Tratado de Educação Ambiental para Sociedades Sustentáveis e Responsabilidade Global", no qual estabeleceu princípios fundamentais da educação para as sociedades sustentáveis, evidenciando a necessidade de "... um pensamento crítico, de um fazer coletivo e solidário, da interdisciplinaridade, da multiplicidade e diversidade" (Jacobi, 2005, p. 242).

A perspectiva cunhada nos espaços institucionais foi sendo incorporada nos demais escopos, como é o caso brasileiro com a consolidação da Lei n 9.795/99, que institui a Política Nacional de Educação Ambiental. Na lei, EA são "... os processos por meio dos quais o indivíduo e a coletividade constroem valores sociais, conhecimentos, habilidades, atitudes e competências voltadas para a conservação do meio ambiente, bem de uso comum do povo, essencial à sadia qualidade de vida e sua sustentabilidade", como destaca o primeiro artigo da Lei n. 9.975 (1999). Percebe-se que, apesar do uso da nomenclatura Educação Ambiental, o conceito de EA da lei não corresponde às perspectivas naturalistas ou conservacionistas (Sauvé, 2005), já que não só aborda a preocupação com o meio ambiente "... em sua totalidade, considerando a interdependência entre o meio natural, o sócioeconômico e o cultural, sob o enfoque da sustentabilidade", como expresso no segundo inciso do primeiro artigo da Lei n. 9.795 (1999), quando estabelece o vínculo com a sustentabilidade e a qualidade de vida.

Seguindo na mesma linha, Dias (2004, p. 523) conceitua EA como "... um processo permanente no qual os indivíduos e a comunidade tomam consciência do seu meio ambiente e adquirem conhecimentos, valores, habilidades, experiências e determinação que os tornem aptos a agir e resolver problemas ambientais, presentes e futuros". Assim, a EA, com um caráter permanente, orientado para o futuro e enfoque interdisciplinar, tem um vínculo direto com as perspectivas de sustentabilidade e com o próprio conceito de Desenvolvimento Sustentável amplamente difundido pela Comissão de Brundtland, instituída pelo World Comission on Environment and Development (WCED, 1987, p. 54): "... aquele que atende às necessidades do presente sem comprometer a possibilidade das gerações futuras de atenderem as suas próprias necessidades".

De acordo com Reigota (2012), a EA não pode limitar-se ao acúmulo de conhecimentos, mas deve selecionar e interpretar os conhecimentos disponiveis sem perder de vista que o objetivo principal é

OS, Organizações e Sustentabilidade, 7(1), p. 102-118, Londrina, PR, jan./jun. 2019.

ISSN 2318-9223, http://www.uel.br/revistas/uel/index.php/ros/issue/view/1535/showToc 
fazer com que esse conhecimento possibilite e amplie a participação política e social de todos os sujeitos do processo educativo. A abordagem de Reigota (2012) concorda com a perspectiva de Jacobi (2003), que diz que a EA deve ser vista como um processo de constante aprendizagem que valorize as diversas formas de conhecimento, além de formar cidadãos com consciência local e global.

Parte dessas abordagens são fruto da "evolução" do conceito de Educação Ambiental e das novas concepções de meio ambiente ao longo do tempo, mas não são só oriundas disso. De acordo com o Relatório Final da Conferência de Tbilisi (UNESCO, 1977, p. 6), a UNESCO, em um estágio inicial, de fato apenas se preocupou com os problemas de cunho ambiental, "... mas o conceito de meio ambiente evoluiu: inicialmente confinado aos seus aspectos físicos e biológicos, agora também cobre o ambiente social, econômico e tecnológico".

Essa abordagem coaduna com a perspectiva de Monroe (2012) ao alegar que o conceito de EA da Declaração de Tbilisi inclui uma gama de outras dimensões ao meio ambiente, e lembra o primeiro dos três objetivos da Educação Ambiental daquele documento, que encoraja o esclarecimento acerca de interdependências econômicas, sociais, políticas e ecológicas em áreas urbanas e rurais (UNESCO, 1977). Assim, Monroe (2012) indica que os seguidores de William Stapp (pesquisador e vice-chairmen da Comissão de Tbilisi) sempre viram a EA como o que hoje vem sendo debatido como EpS ou ESD, contudo alerta que práticas e conceituações conservadoras de EA permitiram esse distanciamento maior da perspectiva mais ampla e interdisciplinar.

A existência de mais de uma concepção de EA (Sauvé, 2005) pode, então, ter viabilizado que a comunidade acadêmica percebesse um distanciamento maior entre EA e EpS.

Esse distanciamento é retratado por McKeown e Hopkins (2007). Para os autores, há semelhanças e diferenças significativas entre os conceitos. Tendo como base os documentos de origem e uma reflexão sobre as pesquisas dos dois temas até aquele momento, os autores perceberam que há estudos e ações de EA que se assemelham à perspectiva de EDS, contraditando a perspectiva de que a Educação Ambiental teria ênfase maior no ambiente. Contudo, McKeown e Hopkins (2007) se preocupam com tal abordagem, pois consideram relevante o distanciamento entre as duas. Para os autores, a EA tem como base o conceito de que os humanos são parte da natureza, em uma perspectiva ambiental. Já a EDS é mais centrada nos humanos, no balanço entre interesses ambientais, sociais e econômicos. Se os dois conceitos se tornarem um só, poderia haver uma perda se "... a EA se tornar uma EDS humano-centrada" (McKeown e Hopkins, 2007, p. 20).

A despeito dessa preocupação, há estudiosos que consideram os termos como sinônimos. É o caso de Guerra et al. (2016). Os autores fazem uma retomada da discussão sobre a distinção entre os conceitos, mas, lembrando de Kopnina (2015) e outros, optam por os considerar como sinônimos.

Já Sterling (2016, 2014), Figueiró et al. (2016) e Sidiropoulos (2014) preferem o uso de Educação para Sustentabilidade ou para o Desenvolvimento Sustentável. Sterling (2014, p. 91) considera que:

\footnotetext{
o movimento da Educação para o Desenvolvimento Sustentável e movimentos educacionais relacionados se preocupam em identificar e avançar em tipos de políticas e práticas de educação, ensino e aprendizagem que parecem ser requeridas se estivermos preocupados em assegurar viabilidade e bem-estar sociais, econômicos e ecológicos, agora e em um futuro de longo prazo.
}

Esta abordagem concorda com a de Brunstein, Godoy e Silva (2014), que dizem que a Educação para a Sustentabilidade deve promover o estabelecimento de metas de longo prazo conjugadas com ações imediatas a fim de motivar indivíduos a agir, estabelecendo niveis de relevância e dando a direção a seguir. Dessa forma, a realidade atual exige uma reflexão cada vez menos linear e isto se produz na inter-relação dos saberes e das práticas coletivas, criando identidades e valores comuns e ações solidárias, numa perspectiva que privilegia o diálogo entre saberes (Jacobi, 2003).

OS, Organizações e Sustentabilidade, 7(1), p. 102-118, Londrina, PR, jan./jun. 2019. 
Figueiró et al. (2016, p. 2) se fundamentam, entre outros, em Sterling para estabelecer seu conceito de EpS, indicando que foca na "... educação de indivíduos com conhecimentos, habilidades e entendimentos necessários para tomar decisões com base em implicações ambientais, sociais e econômicas". Os autores também citam Sidiropoulos (2014), que indica EpS e EDS como sinônimos.

As perspectivas de EpS e EDS combinam com a conceituação da UNESCO (2017, p. 7), que determina uma "... educação holística e transformacional que direciona conteúdos e resultados de aprendizagem, pedagogia e ambiente de aprendizagem". O documento que discute os objetivos da EDS reitera a diferença entre essa e a EA, indicando que o trabalho de Educação para 0 Desenvolvimento Sustentável se relaciona com "... educação para cidadania global, educação para os direitos humanos, Educação Ambiental e outros" (UNESCO, 2017, p. 8).

Considerando apenas o conceito de EpS, Côrtes e Rodrigues (2016) fizeram um estudo bibliométrico para compreender a evolução da produção sobre o assunto em duas bases de dados. Os dados apontaram que, embora houvesse registros de artigos científicos em 1993, as ocorrências vieram a ser mais significativas nos últimos anos, com maior incidência na Década da Educação para o Desenvolvimento Sustentável, de 2005 a 2014.

Para Cadotti (2008), a Década da Educação para o Desenvolvimento Sustentável se constitui grande oportunidade de renovação dos currículos dos sistemas formais de educação, além de resgatar a história de lutas por uma cultura da sustentabilidade, desde Estocolmo (1972), passando pelo Nosso Futuro Comum (1987), pela Rio-92, pelo Fórum de Educação de Dakar (2000) e pelos Objetivos do Milênio (2002). Tais lutas são refletidas em ambos os conceitos aqui discutidos. Assim, este estudo bibliométrico se justifica, ao poder caracterizar as escolhas dos acadêmicos em administração em eventos significativos no âmbito brasileiro.

\section{MÉTODO DE PESQUISA}

O presente estudo segue o método histórico (Silva, 2008), uma vez que tem o propósito de mapear, por meio de um estudo bibliométrico, as características do portfólio bibliográfico sobre "Educação Ambiental" e "Educação para a Sustentabilidade" em três grandes eventos da área de Administração: EnANPAD, ENGEMA e Ecoinovar. Isso, porque, com o mapeamento dos artigos, temse condições de reconstruir o passado e identificar quais as tendências para futuras pesquisas. Para tanto, considerou-se a identificação e seleção de artigos que continham, no título, resumo e/ou palavras-chave, o termo "Educação", já que alguns anais de eventos disponibilizavam sistemas de buscas mais completos e outros precários, eventualmente se limitando à disponibilização da lista dos artigos. Foram automaticamente descartados os artigos sem relação com "meio ambiente" ou "sustentabilidade". Dos 79 (setenta e nove) artigos encontrados, analisou-se brevemente o resumo e/ou introdução para identificar se tratavam das discussões de "Educação Ambiental" ou "educação para sustentabilidade", o que eliminou outros 18 (dezoito) artigos.

No que concerne a abordagem metodológica, o estudo se enquadra como exploratório, descritivo e documental, uma vez que se propõe a identificar os artigos que adotam as terminologias supracitadas, ao mesmo tempo em que permite apontar o que se tem escrito sobre o assunto e descrever como os trabalhos são desenvolvidos (Beuren, 2013). Pela própria natureza e indicadores utilizados, o estudo configura-se como bibliométrico e sociométrico (Okubo, 1997), uma vez que permite elencar quais áreas estão saturadas ou carecem de maior atenção por parte dos pesquisadores, bem como identificar como são estabelecidas as redes de cooperação entre autores e IES. O estudo configura-se ainda como do tipo quali-quanti, uma vez que se vale da análise de conteúdo dos artigos, de modo a extrair as informações pertinentes ao estudo bibliométrico e estabelecer as redes, bem como avaliar quantitativamente os aspectos metodológicos.

OS, Organizações e Sustentabilidade, 7(1), p. 102-118, Londrina, PR, jan./jun. 2019.

ISSN 2318-9223, http://www.uel.br/revistas/uel/index.php/ros/issue/view/1535/showToc 
Quanto ao recorte temporal, o estudo segue os preceitos longitudinais (Malhotra, 2012), uma vez que considera tudo o que foi publicado nos anais disponiveis online de cada evento, considerando o período de 1997 a 2016. Nessa conjuntura, os dados coletados são de origem primária, uma vez que são coletados e sistematizados com a finalidade de responder ao problema de pesquisa proposto (Malhotra, 2012). Destaca-se que o processo de coleta adotou como técnica o uso de um checklist, contendo elementos relacionados ao objetivo do trabalho, objeto de estudo, termo utilizado, enquadramento metodológico, universo e amostra, técnica de análise e principais recomendações apresentadas nos artigos. Tudo isso, de modo a operacionalizar a execução da pesquisa e reunir os elementos necessários para responder ao problema proposto (Beuren, 2013).

Ao definir quais artigos passariam pelo crivo de análise proposto, destaca-se que se fez uso da amostragem não probabilística por acessibilidade ou conveniência (Malhotra, 2012). Isso, porque só foi possivel contemplar na presente pesquisa os artigos que estavam aptos para download nos anais do EnANPAD, ENGEMA e Ecoinovar, o que totalizou 61 (sessenta e um) trabalhos. Salienta-se que, com a análise de conteúdo dos artigos e o preenchimento do checklist, os dados referentes aos aspectos metodológicos foram tabulados na planilha eletrônica do Microsoft Excel ${ }^{\circledR}$ (Office 2013), de onde se extraiu a estatística descritiva de frequência e percentual. Já os dados inerentes aos autores e IES foram organizados na planilha eletrônica em forma de matriz e transportados para a versão de teste do software Ucinet ${ }^{\circledR}$, o que possibilitou a construção das redes de cooperação.

\section{RESULTADO DA PESQUISA, ANÁLISES E DISCUSSÕES}

Com o mapeamento dos artigos que discutem sobre "Educação Ambiental" e/ou "Educação para a Sustentabilidade", constatou-se que há um total de 61 (sessenta e um) artigos disponíveis para análise, dos quais, 4 (quatro) no EnANPAD, 38 (trinta e oito) foram publicados no ENGEMA e 19 (dezenove) no Ecoinovar. Ao proceder com a análise de conteúdo dos artigos, nota-se que 13,11\% (8) deles fazem algum tipo de confusão com o uso do termo, caracterizado pelo uso das duas nomenclaturas como sinônimas. Classifica-se aqui como "confusão" porque os autores desses artigos não explicitam a escolha por utilizar os termos como sinônimos, apenas os alternam sem apresentar uma posição teórica para isso.

Os dados também apontam que 70,49\% (43) dos estudos analisados adotam o termo "Educação Ambiental" ao desenvolverem seus trabalhos, o que se justifica ao se analisarem as referências utilizadas para conceituar o termo. Entre as principais destaca-se o uso da Lei n. ${ }^{\circ}$ 9.795/1999, que trata da Política Nacional de Educação Ambiental e a inclusão da "Educação Ambiental" como componente curricular a ser discutido desde a educação básica até a superior, que é adotado por $55,81 \%$ (24) dos artigos publicados com o referido termo. Já entre aqueles que adotam "Educação para a Sustentabilidade", observa-se que o relatório de monitoramento global da educação, emitido pela UNESCO (2016), é utilizado como referência básica para conceituação de 70\% (7), dos 10 (dez) trabalhos que discutem o referido termo.

Analisando o número de publicações, observa-se que o portfólio bibliográfico da autora Giesta (2008, 2010, 2012, 2014, 2015) é dedicado ao conceito de "Educação ambiental", tanto no ENCEMA (3) como no Ecoinovar (2). Já os estudos de Madruga (2013, 2016), publicados no ENGEMA (2) e Ecoinovar (1), versam sobre "Educação para a Sustentabilidade" (3). Nos trabalhos publicados por Trevisan (2015, 2016), nota-se que ele não segue um único conceito, uma vez que escreve tanto sobre a perspectiva da EA (1), no Ecoinovar, como da EpS (2), no ENGEMA.

Os trabalhos escritos por Barbieri (1997, 2004, 2007), Dias (1992, 1994, 2000, 2002, 2003, 2004 , 2006), Jacobi (2003, 2005, 2006) e Tozzoni-Reis (2001, 2004, 2006 e 2008), também são comumente citados nos trabalhos publicados no EnANPAD, ENGEMA e Ecoinovar, que adotam a terminologia de "Educação Ambiental" em seus estudos. Observa-se que esses autores adotam a nomenclatura Educação Ambiental (EA) na perspectiva que a caracteriza por incorporar as

OS, Organizações e Sustentabilidade, 7(1), p. 102-118, Londrina, PR, jan./jun. 2019.

ISSN 2318-9223, http://www.uel.br/revistas/uel/index.php/ros/issue/view/1535/showToc 
dimensões social, política, econômica, ecológica e ética, o que sugere considerar todas as dimensões ao tratar de qualquer problema ambiental.

Já os trabalhos sobre "Educação para a Sustentabilidade" usam como referência os trabalhos de Barbieri e Silva (2011b), Barbieri (2012) e Jacobi, Raufflet e Arruda (2011). Verifica-se que esses autores defendem que, embora Educação Ambiental e Educação para a Sustentabilidade sejam concepções diferentes, elas acabam se complementando. Aqueles que confundem o uso da terminologia, ou seja, no próprio corpo do texto as adotam sem fazer qualquer distinção ou anúncio de que seguem o mesmo conceito, citam os trabalhos de Dias (1994) e Jacobi (2003). Percebe-se, então, uma semelhança nos autores abordados em todos os artigos, com exceção da Lei de EA e do documento da UNESCO, que parecem ser os maiores definidores teóricos de diferenciação entre as abordagens. Vale destacar que apenas foram verificadas as primeiras seis referências de resgate teórico por artigo. Outras conjecturas poderiam ser feitas caso todas as referências fossem analisadas.

Sobre os objetivos propostos, constata-se que parte deles foi construído com vias a deixar claro o seu propósito de pesquisa: identificar, analisar, verificar, evidenciar, examinar. Contudo, outros indicavam mais a prestação de um serviço ou realização de uma consultoria do que uma pesquisa científica: aumentar, sensibilizar, apresentar, gerar, incentivar, propor, o que pode ser justificado pelo fato de que alguns dos eventos analisados recebem casos práticos. Como os artigos disponiveis não tinham a informação se eram apresentações de casos práticos ou estudos científicos, não é possivel concluir que este foi o fator motivador do uso desses verbos.

Quanto ao objeto ou unidade de análise, nota-se que a maioria dos trabalhos buscam tratar sobre a "Educação Ambiental" no ambiente escolar, considerando as percepções dos docentes e/ou discentes, da educação básica, profissional ou complementar, ao passo em que os que abordam a "Educação para a Sustentabilidade", em cursos de graduação, pós-graduação ou organizações empresariais.

No que concerne aos aspectos metodológicos, constatou-se que 95,08\% (58) dos trabalhos não fazem qualquer menção ao método de pesquisa utilizado (comparativo, dedutivo, dialético, estatístico, indutivo, hipotético-dedutivo, histórico e monográfico). Entre aqueles que anunciam o método, observa-se que os trabalhos da área se declaram como comparativos, dedutivos ou indutivos. O método comparativo pauta-se pela análise de similaridades e diferenças entre indivíduos, empresas ou períodos. Por outro lado, os estudos dedutivos são aqueles que nascem de premissas e lógicas universais para serem generalizadas. Já os estudos indutivos são construídos partindo de inferências e conjecturas oriundas de fatos particulares ou evidências.

Quanto à abordagem da pesquisa, verificou-se que 95,08\% (58) dos trabalhos desenvolvidos com a temática de "Educação Ambiental" e "Educação para a Sustentabilidade" também têm dificuldade em deixar claro qual enfoque adota. Entre os que expressam o aspecto metodológico utilizado, destacam-se trabalhos que se enquadram como empíricos ou fenomenológico. Os trabalhos empíricos possibilitam a análise da face observável da realidade (Martins \& Theóphilo, 2007). Já a fenomenologia segue uma lógica positivista, no sentido de avaliar as funções e sistematizações da sociedade (Marconi \& Lakatos, 2003). Vale destacar que as dificuldades encontradas pelos autores ao expressar metodologia ou abordagem de pesquisa podem ser devido às escolhas que o autor precisa fazer ao se deparar com limitações de espaço na produção dos artigos, especialmente para eventos. Assim, o autor pode optar por dedicar maior atenção ao detalhamento operacional da metodologia ao invés das abordagens mais amplas de epistemologia e ontologia, o que não quer dizer que essas decisões metodológicas não tenham sido tomadas, apenas não foram expostas.

Analisando as estratégias de pesquisa anunciadas pelos autores, nota-se que $29,51 \%$ (18) apontam o uso da estratégia do tipo exploratória, como ilustrado no Quadro 1. Segundo Beuren (2013), esse tipo de estratégia destina-se a estudos cujo propósito consiste em conhecer, com maior 
profundidade, o assunto objeto de análise. A adoção da bibliografia e da estratégia descritiva é anunciada por 26,23\% (16) dos pesquisados. É bom recordar os pressupostos de Beuren (2013), que dizem que a bibliografia se destina a construção da fundamentação teórica de qualquer trabalho acadêmico e a descrever as principais características do objeto de análise, respectivamente. Assim, como é inerente a toda pesquisa, não seria necessário indicá-la como procedimento metodológico. Em alguns casos, análise semelhante pode ser feita à estratégia "documental".

QUADRO 1 - ESTRATÉGIAS DE PESQUUISA

\begin{tabular}{|l|l|l|}
\hline Estratégia & Frequência & Percentual $^{*}$ \\
\hline Bibliográfica & 16 & $26,23 \%$ \\
\hline Exploratória & 18 & $29,51 \%$ \\
\hline Levantamento & 7 & $11,48 \%$ \\
\hline Estudo de caso & 10 & $16,39 \%$ \\
\hline Documental & 15 & $24,59 \%$ \\
\hline Descritiva & 16 & $26,23 \%$ \\
\hline Outras estratégias & 8 & $13,11 \%$ \\
\hline Estudo de campo & 3 & $4,92 \%$ \\
\hline Outras estratégias abordadas & 7 & $11,48 \%$ \\
\hline $\begin{array}{l}\text { Estratégias de pesquisa não } \\
\text { identificada }\end{array}$ & 8 & $13,11 \%$ \\
\hline
\end{tabular}

*Percentual definido em função do número de artigos (61).

Fonte: dados da pesquisa.

Os dados indicam também o uso frequente de estudos fundamentados na estratégia documental $(24,59 \%)$ e no estudo de caso (16,39\%). A estratégia documental caracteriza-se por se valer da análise de materiais que ainda não receberam um tratamento analítico e de onde se pode extrair dados, informações e evidências sobre os fatos pesquisados (Martins \& Theóphilo, 2007). Já os estudos de caso consideram o uso aprofundado, exaustivo e concentrado de um único caso, o que requer a triangulação das informações para garantir maior confiabilidade científica (Beuren, 2013).

No tocante do recorte temporal, 21,31\% (13) dos artigos não deixam essa informação clara, sendo difícil a classificação, ao passo em 68,85\% (42) apontam o uso do recorte transversal, ao destacar o período de coleta de dados. Nos estudos transversais, a amostra só é abordada uma única vez para responder ou participar da pesquisa, sendo ela direcionada para retratar um fato em um dado momento no tempo (Malhotra, 2012). Já 9,84\% (6) dos estudiosos apontam características que permitem enquadrar seu recorte temporal como longitudinal, ou seja, considera a análise acurada de uma empresa ou fato em mais de um período no tempo (Malhotra, 2012).

A respeito da origem dos dados, observou-se que 19,67\% (12) dos autores declararam fazer uso de dados primários e secundários para responder ao problema de pesquisa proposto, ao passo em que $22,95 \%$ (14) não deixaram claro como os dados foram obtidos. No que concerne aos dados primários, assinalados por $37,70 \%$ (23) dos autores, estes se referem aos dados de primeira mão, que foram coletados e produzidos com a finalidade de responder ao problema de pesquisa proposto, sendo comumente obtido com o uso de questionários ou entrevistas (Malhotra, 2012). Os dados secundários, adotado em 19,67\% (12) dos estudos, são oriundos de publicações já existentes sobre 0 assunto e sobre as quais há um custo menor de aquisição ou produção (Beuren, 2013).

Em relação às técnicas de coleta declaradas pelos autores pesquisados como utilizadas em seus estudos, percebe-se que 36,07\% (22) não deixam claro qual a técnicas adotada para coletar os dados a serem analisados, como ilustrado no Quadro 2. Apesar disso, observa-se que $34,43 \%$ (21) dos artigos fazem uso do questionário e 32,79\% (20) do roteiro de entrevista, como requerido em

OS, Organizações e Sustentabilidade, 7(1), p. 102-118, Londrina, PR, jan./jun. 2019. 
estudos com dados primários. Segundo Martins e Theóphilo (2007), o questionário abarca um conjunto ordenado de perguntas e variáveis de pesquisa a serem respondidas pelos indivíduos que compõem a população ou amostra pesquisada. Destaca-se que, apesar de o roteiro de entrevista seguir a mesma lógica, ele é realizado pelo pesquisador sem que o indivíduo que se enquadra como objeto de análise fique preso a um papel, o que Ihes dá mais liberdade de resposta (Beuren, 2013).

QUADRO 2 - TÉCNICAS DE COLETA

\begin{tabular}{|l|l|l|}
\hline Técnica & Frequência & Percentual* $^{*}$ \\
\hline Questionário & 21 & $34,43 \%$ \\
\hline Entrevista & 20 & $32,79 \%$ \\
\hline Documentação & 4 & $6,56 \%$ \\
\hline Observação & 5 & $8,20 \%$ \\
\hline Outras técnicas utilizadas & 4 & $6,56 \%$ \\
\hline Técnica de coleta não identificada & 22 & $36,07 \%$ \\
\hline
\end{tabular}

*Percentual definido em função do número de artigos (61). Fonte: dados da pesquisa.

O uso da técnica de observação, apontado em 8,20\% (5) dos artigos, também segue a lógica de uso dos dados primários. Isso, porque ela se vale do uso dos sentidos para perceber e determinar aspectos advindos da realidade, principalmente no que concerne aos fatos e fenômenos que ocorrem ao redor do ambiente de pesquisa (Marconi \& Lakatos, 2003). Entre as demais técnicas utilizadas pelos pesquisadores, observa-se a documentação, bem como a criação de grupos focais e entrevistas individuais e/ou em grupos, com o intuito de coletar dados em um ambiente de discussão e troca de informações.

No que diz respeito à delimitação do objeto de análise, entre fazer o estudo com a população ou universo, ao fazer uso da amostragem probabilística ou não probabilística, constata-se que 55,74\% (34) dos artigos pesquisados não deixam a sua delimitação clara, como ilustrado no Quadro 3. Isso, porque, como o estudo de caso requer a análise exaustiva e aprofundada sobre um único objeto de análise, sobre ele não é possivel definir população ou amostra nem fazer inferência ou generalizações. Já 4,92\% (4) dos trabalhos declaram adotar a amostra probabilística do tipo estratificada, no qual faz-se um recorte da população em dois subgrupos ou estratos para responder ao problema de pesquisa proposto (Malhotra, 2012). O uso desta classificação se deu, muitas vezes, por analogia, uma vez que é sabido que estudos qualitativos têm a tendência de não usar a terminologia "população", "universo", "amostra", já que não buscam generalização e preferem adotar outros termos, como por exemplo "sujeitos".

QUADRO 3 - DELIMITAÇÃO DO OBJETO DE ANÁLISE

\begin{tabular}{|l|l|l|}
\hline Delimitação & Frequência & Percentual \\
\hline População ou universo & 3 & $4,92 \%$ \\
\hline Amostra probabilística & 2 & $3,28 \%$ \\
\hline Amostra não probabilística & 25 & $40,98 \%$ \\
\hline Delimitação do objeto de análise não identificada & 34 & $55,74 \%$ \\
\hline TOTAL & 61 & $100,00 \%$ \\
\hline
\end{tabular}

Fonte: dados da pesquisa.

No que compete aos estudos que destacam fazer uso da amostragem não probabilística (40,98\%), observa-se que eles adotam a amostra do tipo intencional (2) ou por acessibilidade ou conveniência (23). A primeira caracteriza-se por reunir indivíduos selecionados de forma proposital para participar da pesquisa, seja em função do julgamento do pesquisador ou por se compreender que os indivíduos que irão responder ao estudo devem ser especialistas (Malhotra, 2012). Já o segundo é aplicado em situações em que os indivíduos são selecionados ao acaso para participar da pesquisa e sobre os quais não se observa qualquer rigor técnico (Beuren, 2013). 
Com relação à análise de dados, observou-se que 60,66\% (37) dos estudos não deixam claros quais os critérios e/ou técnicas utilizadas para analisar ou avaliar os dados coletados e, com isso, responder ao problema de pesquisa de pesquisa proposto, como apresentado no Quadro 4. Ademais, 3,28\% (2) dos artigos se enquadram como do tipo quali-quanti e utilizam, de forma combinada, a estatística descritiva e a análise de conteúdo. Tudo isso sugere a realização de estudos que contemplam o uso de questionários ou entrevistas que fazem uso de perguntas com respostas fechadas e abertas.

QUADRO 4 - TÉCNICA DE ANÁLISE DE DADOS

\begin{tabular}{|l|l|l|}
\hline Técnica & Frequência & Percentual \\
\hline Quantitativa & 15 & $24,59 \%$ \\
\hline Qualitativa & 12 & $19,67 \%$ \\
\hline Quali-quanti & 2 & $3,28 \%$ \\
\hline Técnica de análise de dados não descrita & 37 & $60,66 \%$ \\
\hline TOTAL & 61 & $100,00 \%$ \\
\hline \multicolumn{2}{|c|}{ Fonte: dados da pesquisa. } \\
\hline
\end{tabular}

Os dados apontam que $24,59 \%$ dos estudos publicados adotam técnicas advindas, exclusivamente, da análise quantitativa, uma vez que fazem uso da estatística descritiva, análise multivariada de dados e análise do tipo não paramétrica. Segundo Martins e Theóphilo (2007), a estatística descritiva sugere a organização e sistematização dos dados, com vias a propiciar a descrição dos achados, sendo essa uma técnica de natureza preliminar e pouco robusta. Já a adoção da análise multivariada aponta a necessidade de se adotar técnicas mais robustas, que permitem avaliar o poder explicativo das variáveis, como observado em estudos que seguem os preceitos da análise fatorial (Malhotra, 2012). Já os estudos não paramétricos são utilizados quando o pressuposto de homogeneidade das variáveis entre os grupos não se confirma (Marôco, 2011).

Em relação às redes de cooperação estabelecida pelos autores pesquisados, constata-se que há grupos consolidados que atuam conjuntamente na elaboração de trabalhos relacionados à temática, como ilustrado na Figura 1. Entre os principais grupos, destacam-se o liderado por Silvia Donizete Santos (DONIZETE-SANTOS), em rosa, que possui graduação em Farmácia e mestrado em Gestão de Organizações Públicas, atuando como técnica de laboratório da Universidade Federal de Santa Maria (UFSM). A autora Vânia Medianeira Flores Costa (FLORES-COSTA), com quem estabelece parceria, é quem detém um grupo de pesquisa na área de Administração e Gestão de pessoas, que conta com a participação dos demais componentes do artigo como pesquisadores em treinamento no nível de graduação, mestrado ou doutorado. 
FIGURA 1 - REDE DE COOPERAÇÃO ENTRE AUTORES

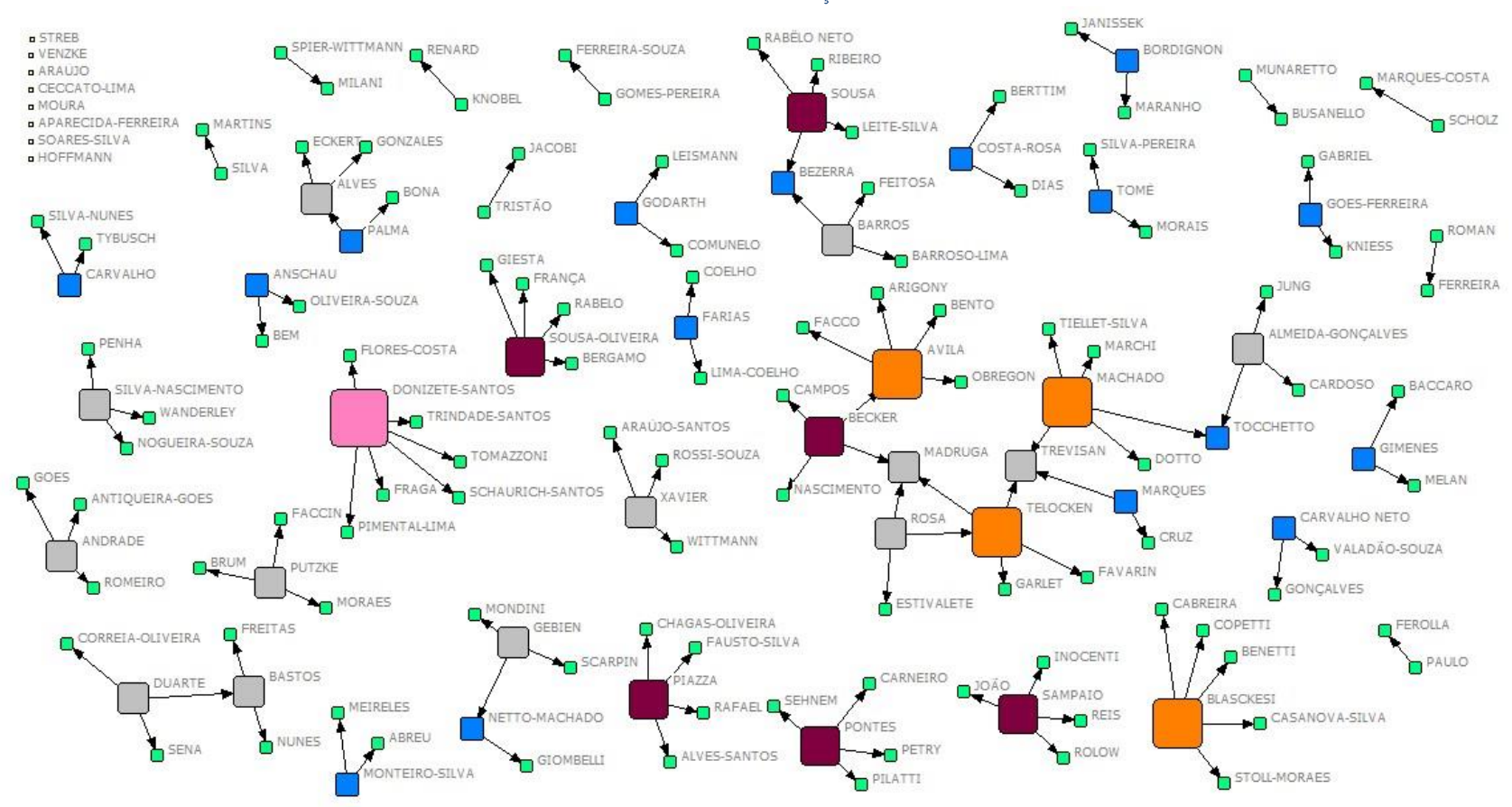

Fonte: dados da pesquisa.

A autora FLORES-COSTA atua na mesma instituição que a DONIZETE-SANTOS, momento em que desenvolveram algumas atividades de pesquisa em conjunto, que culminou com um trabalho de orientação no mestrado. A DONIZETE-SANTOS também atua em outras atividades acadêmicas, como membro do corpo editorial do Programa Nacional de Administração Pública (PNAP) e assessora algumas agências de fomento à pesquisa, nacionais e internacionais, como a International Stress Management Association e a Comissão Interinstitucional de Educação Ambiental. Ainda desenvolve pesquisas na área de Administração, orienta trabalhos acadêmicos de alunos dos mais diversos níveis de formação, bem como atua como revisora de periódicos tais como a Revista de Administração da UFSM, Gestão \& Regionalidade, Base (UNISINOS), Revista Sociais e Humanas e Revista psicologia: organizações e trabalho.

O trabalho escrito por Tharso José Foletto Blasckesi (BLASCKESI), em Iaranja, também chama atenção pela quantidade de laços estabelecidos com outros autores. Ao analisar o seu currículo, observa-se que possui graduação em Gestão ambiental e está com mestrado em andamento em Engenharia Agrícola na Universidade Federal do Pampa (UNIPAMPA). Ele também atua em projetos de pesquisa relacionados ao meio ambiente, é membro do Comitê de Gerenciamento da Bacia Hidrográfica Rios Vacacai e Vacacai-Mirim e revisor dos periódicos Revista eletrônica em Gestão, Educação e Tecnologia Ambiental e Disciplinarum Scientia.

Destaca-se que todos os autores vinculados ao BLASCKESI estão vinculados a Luciana Borba Banetti (BANETTI), doutora em Engenharia ambiental pela Universidade Federal de Santa Catarina (UFSC) e docente da UNIPAMPA, que atua na graduação e desenvolve estudos na área de Educação Ambiental. Ela também desenvolve projetos de pesquisa relacionados à sustentabilidade e de extensão sobre "Educação Ambiental", inclusive coordenando o Programa de Educação Ambiental da UNIPAMPA. Ademais, ministra a disciplina de "Educação Ambiental" no curso de graduação em Gestão ambiental e Engenharia florestal.

No que concerne a maior rede de autores estabelecida, na qual incluem-se Lucas Veiga Ávila (ÁVILA), Suelen Geíse Telocken (TELOCKEN), Emanuelly Comoretto Machado (MACHADO), destaca-se que eles estão vinculados a cursos de pós-graduação, em nível de mestrado ou doutorado, na UFSM. 0 autor ÁVILA é docente e pesquisador da Universidade Estadual do Rio Grande do Sul (UERGS) e

OS, Organizações e Sustentabilidade, 7(1), p. 102-118, Londrina, PR, jan./jun. 2019. 
desenvolve trabalhos acadêmicos com a Lúcia Rejane da Rosa Cama Madruga (MADRUGA) desde 2012. Coordena um projeto de pesquisa relacionado a estratégias e ensino voltados à sustentabilidade; também atua como membro editorial da Revista de Gestão e Organizações Cooperativas (RCC) e revisor da RAMA: Revista em Agronegócio e Meio Ambiente, Innovare, International Journal of Management and Business Research, Revista Cesto, Revista Gestão Universitária na América Latina (GUAL) e a revista Reunir: Revista de Administração, Ciências Contábeis e Sustentabilidade.

A autora TELOCKEN está cursando o mestrado em Administração pela UFMS. Desenvolveu alguns trabalhos acadêmicos relacionados à discussão da sustentabilidade e atua em um projeto de pesquisa que discute negócios sustentáveis. A autora MACHADO também está com seu mestrado em andamento, enquadra-se como bolsista de pesquisa institucional, produzindo trabalhos acadêmicos relacionados à sustentabilidade. Nessa perspectiva, observa-se que ambas estão no mesmo programa de pós-graduação, assim como parte dos demais colegas da rede, que agem cooperativamente na elaboração de artigo científico sobre sustentabilidade.

Com relação à análise institucional, ilustrada na Figura 2, nota-se que há uma rede de cooperação forte entre as universidades do sul do Brasil: UFRGS, UFSM e UNIPAMPA. Isso se justifica pelos programas de pós-graduação e grupos de pesquisa existentes nas referidas instituições, em especial o Grupo de Pesquisa em Sustentabilidade da UFRGS, liderado pelo pesquisador Luis Felipe Machado do Nascimento (NASCIMENTO), assim como a proximidade geográfica dessas IFES. Os elos regionais parecem ser relevantes para o estabelecimento das redes institucionais, já que, além da rede preconizada por universidades gaúchas, destacam-se redes da região nordeste, com instituições como UFPI, UFPB e FLF, outra com UECE e UNIFOR, ambas de Fortaleza-CE, outro nó com instituições predominantemente paulistas (UNESP, UNASP, FCDA) e outro com predominância catarinense (UNC e SOCIESC). Observa-se, contudo, que tal elemento regional não é determinante na rede, já que há relacionamentos destas com instituições de outras regiões do país. Tais relações podem se dar por estabelecimento de orientações e/ou ex-orientações, assim como atuação dos pesquisadores em mais de uma instituição ao longo da sua carreira acadêmica.

FIGURA 2 - REDE DE COOPERAÇÃO ENTRE IES

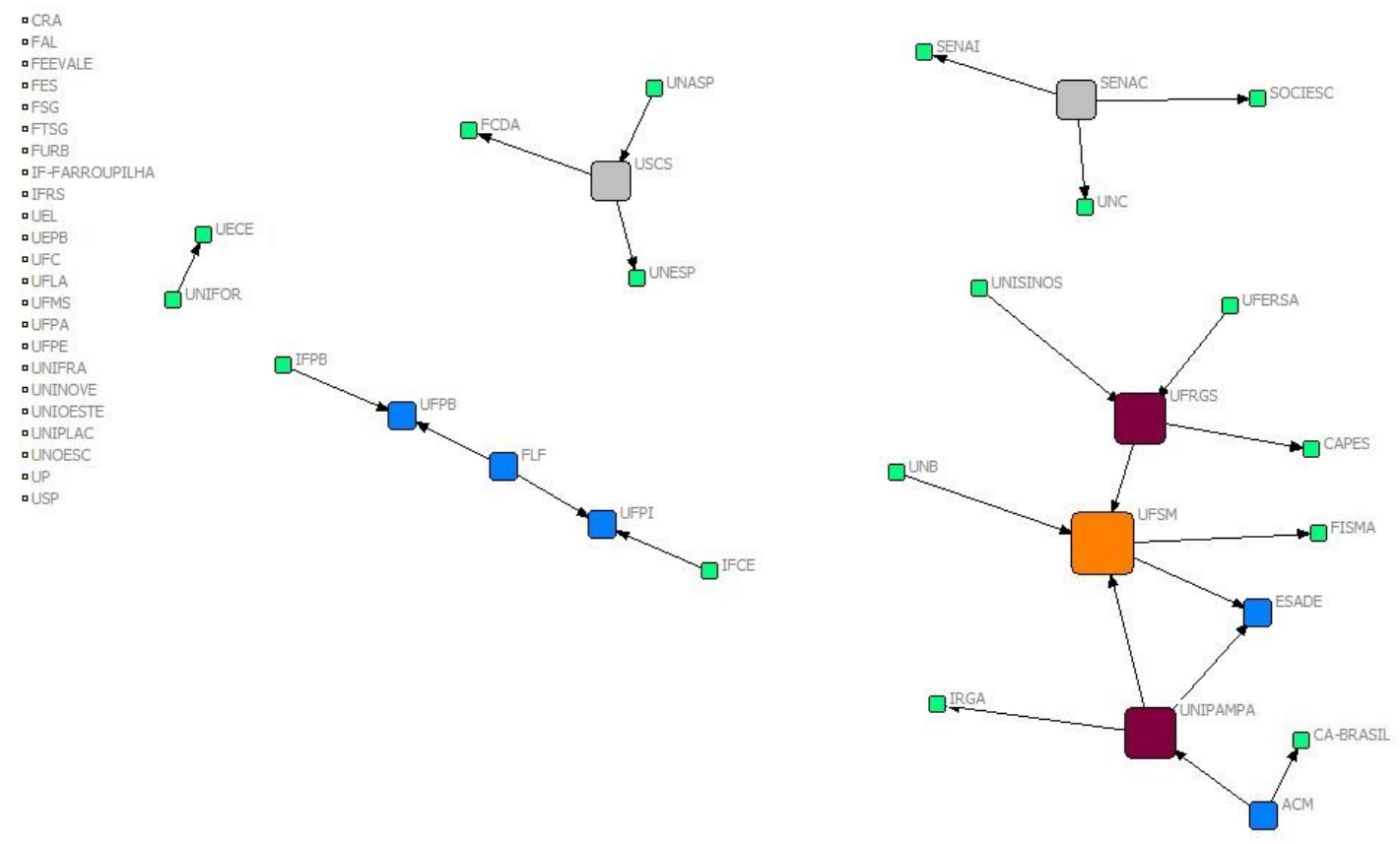

Fonte: dados da pesquisa.

OS, Organizações e Sustentabilidade, 7(1), p. 102-118, Londrina, PR, jan./jun. 2019.

ISSN 2318-9223, http://www.uel.br/revistas/uel/index.php/ros/issue/view/1535/showToc 
Ao analisar que nomenclaturas são utilizadas pelas instituições de ensino, percebe-se que a maioria dos usos de "Educação para a Sustentabilidade" são de autores vinculados a universidades do sul do país, em especial UFRGS e UFSM. Isso pode se justificar pela atuação do GPS e suas ramificações por orientações e relacionamentos com egressos de cursos de graduação e/ou pós-graduação.

Por fim, identificaram-se propostas para estudos futuros nas áreas de EA e EpS com a análise dos artigos, geralmente focados nas prerrogativas e objetivos do estudo original. De forma genérica, destacam-se: ampliação de amostra, diversificação da amostra com intuito de efetivar comparação e fazer acompanhamento da amostra para fazer estudo longitudinal no futuro.

\section{CONSIDERAÇÕES FINAIS}

Este estudo teve como objetivo mapear, por meio de um estudo bibliométrico, o que vem sendo produzido sobre "Educação Ambiental" e "Educação para a Sustentabilidade" em três grandes eventos da área de Administração: EnANPAD, ENGEMA e Ecoinovar. Para o atingimento desse objetivo, foram selecionados 61 (sessenta e um) artigos dos eventos supracitados que tinham "Educação" no título e envolvimento com as áreas de sustentabilidade e/ou meio ambiente.

A análise do conteúdo dos artigos foi tabulada na planilha Exce ${ }^{\circledR}$ e Ucinet ${ }^{\circledR}$. É relevante destacar que este estudo levantou a dicotomia entre os termos "Educação Ambiental" e "Educação para a Sustentabilidade". Dificilmente esse debate sobre a definição ocorreu de forma explícita. Em geral, os autores que optaram por "Educação Ambiental" e "Educação para a Sustentabilidade" já tinham sua decisão tomada, têm formação dedicada aos temas que escolheram e atuam na área em ações de ensino, extensão e/ou pesquisa. A maioria optou pela escolha do uso de "Educação Ambiental" (70,49\%), possivelmente considerando as perspectivas mais atuais e não as perspectivas naturalistas e conservacionistas (Sauvé, 2005).

A suposição de que os artigos classificados como tendo feito "confusão" entre os termos se dava porque os autores consideravam os termos como sinônimos não tem como ser confirmada. No entanto, os autores referenciados por eles abordavam tanto EA quanto EpS como aquelas que incluem o elo ambiental, sem excluir os elos social e econômico, numa busca por sustentabilidade (Lei n. 9.795, 1999; Sauvé, 2005; UNESCO, 2017).

Foi observado também que vários artigos apontaram certa fragilidade na apresentação explícita de apontamentos metodológicos. Tal consideração pode significar dificuldades em materializar e externalizar as decisões epistemológicas, metodológicas, ontológicas ou restrição ao número de páginas dos eventos, o que inviabiliza que todas as informações sejam detalhadas, fazendo com que o autor faça escolhas; ou ainda a fragilidade metodológica dos estudos feitos.

A análise realizada, contudo, tem algumas limitações. A primeira e mais flagrante é de que os dados são limitados àqueles disponibilizados online e mediante os mecanismos de busca possíveis. Pode ser, com isso, que artigos sobre EA ou EpS que não utilizassem o termo "Educação" no título, ou que não tivessem disponíveis online, não foram incluídos no estudo. Além disso, a análise se restringiu aos itens alocados como relevantes no checklist, de forma que outras considerações poderiam ser realizadas caso outros tópicos fossem identificados.

Assim, para estudos futuros sugere-se a ampliação da pesquisa para outros eventos e periódicos da área, de forma que estudos comparativos possam ser realizados e uma maior amplitude do mapeamento seja feita. Sugere-se também um acompanhamento dos artigos publicados nos eventos e analisados aqui, de forma a verificar se eles são ampliados, modificados e/ou publicados em periódicos nacionais ou internacionais.

OS, Organizações e Sustentabilidade, 7(1), p. 102-118, Londrina, PR, jan./jun. 2019. 


\section{REFERÊNCIAS}

Araújo, C. A. (2006). Bibliometria: Evolução história e questões atuais. Em Questão, 12(1), 11-32.

Barbieri, J. C. (2012). Gestão ambiental empresarial: Conceitos, modelos e instrumentos (3a ed.). São Paulo: Saraiva.

Barbieri, J. C. (2007). Cestão ambiental empresarial: Conceitos, modelos e instrumentos (2a ed.). São Paulo: Saraiva.

Barbieri, J. C. (2004). A educação ambiental e a gestão ambiental em cursos de graduação em administração: Objetivos, desafios e propostas. Revista de Administração Pública, 38(6), 919-946.

Barbieri, J. C. (1997). Desenvolvimento e meio ambiente: As estratégias de mudança da agenda 21. Petropólis: Vozes.

Barbieri, J. C., \& Silva, D. da (2011a). Desenvolvimento sustentável e educação ambiental: uma trajetória comum com muitos desafios. Revista de Administração Mackenzie, 12(3), edição especial, 51-82.

Barbieri, J. C., \& Silva, D. da (2011b). Educação ambiental na formação do administrador. São Paulo: Cengage Learning.

Beuren, I. M. (coord). (2013). Como elaborar trabalhos monográficos em contabilidade (3a ed). São Paulo: Atlas.

Carvalho, I. (2005). Educação ambiental: Pesquisa e desafios. Porto Alegre: Artmed.

Côrtes, P. L., \& Rodrigues, R. (2016). A bibliometric study on "education for sustainability". Brazilian Journal of Science and Technology, 3(1), 1-17.

Decreto n. 4.281, de 25 de junho de 2002 (2002). Regulamenta a Lei n. 9.795, de 27 de abril de 1999, que institui a Política Nacional de Educação Ambienta, e dá outras providências. 2002. Recuperado de: <http://www.planalto.gov.br/ccivil_03/decreto/2002/d4281.htm>.

Dias, G. F. (2006). Educação e gestão ambiental. São Paulo: Gaia.

Dias, G. F. (2004). Educação ambiental: Princípios e práticas (9a ed.). São Paulo: Gaia.

Dias, G. F. (2003). Educação ambiental: Princípios e práticas (8a ed.). São Paulo: Gaia.

Dias, G. F. (2002). Educação ambiental: Princípios e práticas (7a ed.). São Paulo: Gaia.

Dias, G. F. (2000). Educação ambiental: Principios e práticas (6a ed.). São Paulo: Gaia.

Dias, G. F. (1994). Atividades interdisciplinares de educação ambiental. São Paulo: Global.

Dias, G. F. (1992). Educação ambiental: Princípios e práticas. São Paulo: Gaia.

Figueiró, P. S., Bittencourt, B. A., \& Schutel, S. (2016). Education for sustainability in business schools by practicing social learning. Brazilian Journal of Science and Technology, 3(1), 1-16.

Gadotti, M. (2008). Educar para a sustentabilidade: Uma contribuição à década da educação para o desenvolvimento sustentável. São Paulo: Editora e Livraria Instituto Paulo Freire.

Giesta, L. C. (2009). Educação ambiental e sistema de gestão ambiental em empresas. Tese de Doutorado, Administração, Universidade Federal do Rio Grande do Sul, Porto Alegre, Brasil.

Guerra, J. B. S. O. de A., Garcia, J., Lima, M. de A., Barbosa, S. B., Heerdt, M. L., \& Berchin, I. I. (2016). A proposal of a balanced scorecard for an environmental education program at universities. Journal of Cleaner Production,172(20), 1-17. 
Heimlich, J. E. (2007). Research trends in the United States: EE to ESD. Journal of Education for Sustainable Development, 1(2), 219-227.

Higgins, B., \& Thomas, I. (2016). Education for sustainability in universities: Challenges and opportunities for change. Australian Journal of Environmental Education, 32(1), 91-108.

Jabbour, C. J. C. (2015). Environmental training and environmental management maturity of Brazilian companies with IS014001: Empirical evidence. Journal of Cleaner Production, 96, 331-338.

Jacobi, P. (2006). Educação ambiental e o desafio da sustentabilidade socioambiental. O Mundo da Saúde, 30(4), 524-531.

Jacobi, P. (2003). Educação ambiental, cidadania e sustentabilidade. Cadernos de Pesquisa, 118, 191192.

Jacobi, P. R. (2005). Educação ambiental: O desafio da construção de um pensamento crítico, complexo e reflexivo. Revista Educação e Pesquisa FE-USP, 31(2), 235-242.

Jacobi, P. R., Raufflet, E., \& Arruda, M. P. de. (2011). Educação para a sustentabilidade nos cursos de administração: Reflexão sobre paradigmas e práticas. Revista de Administração Mackenzie, 12(3), 21-50.

Kopnina, H. (2015). Neoliberalism, pluralism and environmental education: The call for radical reorientation. Environmental Development, 15, 120-130.

Lei n. 9.795, de 27 de abril de 1999. (1999). Dispõe sobre a Educação Ambiental, institui a Política Nacional de Educação Ambiental e dá outras providências. Brasília. 1999. Recuperado em 22 abril 2017, de http://www.planalto.gov.br/ccivil_03/leis/I9795.htm.

Malhotra, N. K. (2012). Pesquisa de marketing (6a ed.). Porto Alegre: Bookman.

Marconi, M. A., \& Lakatos, E. M. (2003). Fundamentos de metodologia científica (5a ed.). São Paulo: Atlas.

Marôco, J. (2011). Análise estatística com o SPSS Statistics (5a ed.). ReportNumber: Pero Pinheiro.

Martins, G. A., \& Theóphilo, C. R. (2007). Metodologia da investigação científica para ciências sociais aplicadas. São Paulo: Atlas.

Mckeown, R., \& Hopkins, C. (2007). Moving beyond the EE and ESD disciplinary debate in formal education. Journal of Education for Sustainable Development, 1(1), 17-26.

Monroe, M. C. (2012). The co-evolution of ESD and EE. Journal of Education for Sustainable Development, 6(1), 43-47.

Okubo, Y. (1997). Bibliometric indicators and analysis of research systems: Methods and examples. Paris: OCDE/GD.

Reigota, M. (2012). O que é educação ambiental. São Paulo: Editora Brasiliense.

Resolução n. 2, de 15 de julho de 2012 (2012). Estabelece as Diretrizes Curriculares Nacionais para a Educação Ambiental. 2012. Recuperado em 11 setembro 2017, de http://conferenciainfanto.mec.gov.br/images/pdf/diretrizes.pdf.

Sauvé, L. (2005). Uma cartografia das correntes em educação ambiental. In M. Sato, \& I. Carvalho. Educação ambiental: Pesquisa e desafios. Porto Alegre: Artmed.

Sidiropoulos, E. (2014). Education for sustainability in business education programs: A question of value. Journal of Cleaner Production, 85, 472-487.

Silva, A. C. R. (2008). Metodologia da pesquisa aplicada à contabilidade. São Paulo: Atlas. 
Springett, D. (2014). Luta ideológica: O desenvolvimento sustentável no currículo de Administração. In J. Brunstein, A. S. Godoy, \& H. C. Silva (orgs.). Educação para a sustentabilidade nas escolas de administração. São Carlos: RiMa Editora.

Sterling, S. (2016). A commentary on education and sustainable development goals. Journal of Education for Sustainable Development, 10(2), 208-213.

Sterling, S. (2014). Separate tracks or real synergy? Achieving a closer relationship between education and SD, Post-2015. Journal of Education for Sustainable Development, 8(2), 89-112.

Tozzoni-Reis, M. F. C. (2008). Educação ambiental: Natureza, razão e história (2a ed.). Campina: Autores associados.

Tozzoni-Reis, M. F. C. (2006). Temas ambientais como "temas geradores": Contribuições para uma metodologia educativa ambiental crítica, transformadores e emancipatória. Educar em revista, 27, 93-110.

Tozzoni-Reis, M. F. C. (2004). Educação ambiental: Natureza, razão e história. Campina: Autores associados.

Tozzoni-Reis, M. F. C. (2001). Educação ambiental: Referências teóricas no ensino superior. Interface - Comunicação, Saúde, Educação, 5(9), 33-50.

Tramarico, C. L., Salomon, V. A. P., \& Marins, F. A. S. (2017). Multi-criteria assessment of the benefits of a supply chain management training considering green issues. Journal of Cleaner Production, 142, 249-256.

Organização das Nações Unidas para a Educação, a Ciências e a Cultura (2017). Education for sustainable development goals: Learning objectives. Recuperado em 27 abril 2017, de http://unesdoc.unesco.org/images/0024/002474/247444e.pdf.

Organização das Nações Unidas para a Educação, a Ciências e a Cultura. (1977). Final report: Intergovernmental conference on environmental education organised by UNESCO in co-operation with UNEP. Recuperado em 25 abril 2017, de http://unesdoc.unesco.org/images/0003/000327/032763eo.pdf.

Organização das Nações Unidas para a Educação, a Ciências e a Cultura (2005). United Nations Decade of Education for Sustainable Development (2005-2014): International implementation scheme. Recuperado em 27 abril 2017, de http://unesdoc.unesco.org/images/0014/001486/148654E.pdf.

World Commission on Environment and Development (1987). Report of the World Commission on Environment and Development: Our common future. Oslo: United Nations. 